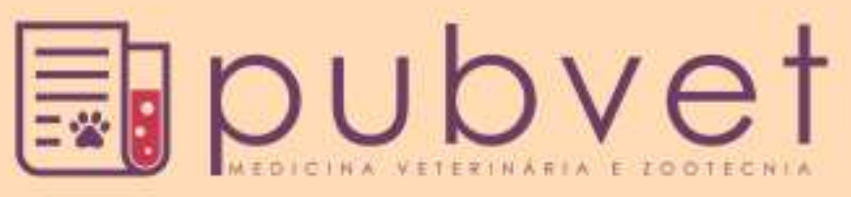

\title{
PCR-RFLP: Uma alternativa a cultura (padrão Ouro) no diagnóstico de dermatófitos em cães e gatos
}

\section{Carlos Adriano de Santana Leal ${ }^{1 *}$, Pomy de Cássia Peixoto Kim ${ }^{1}$, André da Rocha Mota ${ }^{2}$, Débora Costa Viegas de Lima ${ }^{1}$, Ana Lisa do Vale Gomes ${ }^{3}$, José Wilton Pinheiro Júnior ${ }^{3}$, Leonildo Bento Galiza da Silva ${ }^{4}$, Rinaldo Aparecido Mota ${ }^{3}$}

${ }^{I}$ Doutorando (a) em Ciência Animal Tropical, Universidade Federal Rural de Pernambuco, Recife, PE, Brasil.

${ }^{2}$ Médico Veterinário Residente do Hospital Veterinário da Unesp, Botucatu, SP, Brasil.

${ }^{3}$ Professor (a) da Universidade Federal Rural de Pernambuco, Recife, PE, Brasil.

${ }^{4}$ Professor da Universidade Federal Rural da Amazônia, Belém, PA, Brasil.

*Autor para correspondência: c_adrianosl@hotmail.com

RESUMO. Dermatófitos são fungos queratinofílicos e queratinolíticos causadores da dermatofitose em homens e animais, e mesmo com uma variedade de métodos disponíveis, o diagnóstico laboratorial ainda representa uma grande dificuldade na rotina da clínica veterinária. Objetivou-se avaliar a técnica da PCR-RFLP como uma alternativa a cultura na identificação de dermatófitos em cães e gatos. Analisou-se 150 amostras clínicas de animais com dermatopatias. Culturas e extrações de DNA dos pelos e/ou crostas foram realizadas. Colônias de M. canis (URM 6273), M. gypseum (URM 6921) e $T$. mentagrophytes (URM 6211), provenientes da Coleção de Culturas - Micoteca URM Departamento de Micologia, Centro de Ciências Biológicas da Universidade Federal de Pernambuco (CCB/UFPE), foram utilizadas para verificação de padrões de bandas diferenciados que identificassem estas espécies. Os primers utilizados foram ITS 1 e ITS 4. A endonuclease $B s e \mathrm{BI}$ foi a escolhida para a obtenção do padrão de fragmentos. Para o estudo de concordância entre os testes utilizou-se o coeficiente de Kappa $(K)$. Observou-se uma concordância muito boa entre os resultados da cultura e da PCR-RFLP $(K=0.813)$. Conclui-se que a técnica molecular apresentou grande potencial de identificação de dermatófitos em amostras clínicas de cães e gatos, no entanto, ressalta-se a necessidade de se ampliar esses estudos, para futura indicação da PCR-RFLP na rotina laboratorial.

Palavras chave: Dermatofitose, enzima de restrição, espaçadores transcritos internos, micose superficial, rdna

\section{PCR-RFLP: An alternative to culture (gold standard) in diagnosis of dermatophytes in dogs and cats}

\footnotetext{
ABSTRACT. Dermatophytes are fungi keratinophilic and keratinolytic that causing dermatophytosis in humans and animal and, even with a variety of available methods, the laboratory diagnosis is still a difficulty in the veterinary clinic routine. The aim of this study was to evaluate the PCR-RFLP technique as an alternative method to the culture (gold standard) for the diagnosis of dermatophytes in dogs and cats. Were analyzed 150 samples from animals with skin disease. Culture and DNA extraction from fur and/or crusts were performed. To the PCR-RLFP positive controls were used colonies of $M$. canis (URM 6273), M. gypseum (URM 6921) and T. mentagrophytes (URM 6211), from the URM Micoteca - Department of Mycology, Biological Sciences Center of the Universidade Federal do Pernambuco. The primers used were ITS1 and ITS 4. The BseBI endonuclease was selected to obtain fragments pattern. The Kappa coefficient $(\mathrm{K})$ was used to analyze the agreement between culture and PCR-RFLP. There was an almost perfect agreement (K
} 
$=0.813)$ between the results of culture and PCR-RFLP. The molecular technique showed an interesting potential to the dermatophytes identification in clinical samples from dogs and cats. However, further studies are required to guide the future of PCR-RFLP in the laboratory routine.

Keywords: Dermatophytosis, restriction enzymes, Internal transcribed spacers, superficial mycoses, rdna

\section{PCR-RFLP: Una alternativa cultura (estándar de oro) en el diagnóstico de dermatofitos en perros y gatos}

RESUMEN. Los dermatofitos son hongos queratinofílicos y queratinoliticos que causan la tiña en los seres humanos y animales, e incluso con una variedad de métodos disponibles, el diagnóstico de laboratorio representa todavía una gran dificultad en la rutina de la clínica veterinaria. Este estudio tuvo como objetivo evaluar la técnica de PCR-RFLP como una alternativa a la cultura en la identificación de dermatofitos en perros y gatos. Se analizaron 150 muestras clínicas de animales con enfermedades de la piel. Se realizó la cultura y la extracción de ADN de los pelos y / o costras. Colonias de M. canis (URM 6273), $M$ gypseum. (URM 6921) y T. mentagrophytes (URM 6211), provenientes de la Colección de Culturas - Micoteca URM - Departamento de Micología, Centro de Ciencias Biológicas, Universidad Federal de Pernambuco (CCB / UFPE), se utilizaron para comprobar los patrones de bandas diferenciados para identificar estas especies. Los primers utilizados fueron ITS 1 e ITS 4. La endonucleasa BseBI fue elegida para obtener el patrón de fragmentos. Para el estudio de correlación entre las pruebas se utilizó el coeficiente de Kappa $(K)$. Se observó una correlación entre los resultados del cultivo y del PCR-RFLP (K $=0,813)$. Se concluyó que la técnica molecular mostró gran potencial de identificación de dermatofitos en muestras clínicas de perros y gatos, sin embargo, hacen hincapié en la necesidad de ampliar estos estudios, para futura indicación del PCR-RFLP en la rutina del laboratorio.

Palabras clave: Tiña, enzimas de restricción, espaciadores transcritos internos, micosis superficial, ADNr

\section{Introdução}

Dermatófitos são fungos que possuem a capacidade de invadir e multiplicar-se em estruturas queratinizadas causando dermatofitose em homens e animais (Liu et al., 2000, Liu et al., 2002, Quinn et al., 2005, Coelho et al., 2008). Os gêneros mais envolvidos nas infecções em animais são Microsporum e Trichophyton (Muller and Kirk, 1996). Segundo Costa (2010), Microsporum canis, Microsporum gypseum e Trichophyton mentagrophytes são os principais agentes etiológicos das dermatofitoses em cães e gatos, pois são dotados de alta infectividade e baixa patogenicidade e virulência.

O diagnóstico da dermatofitose pode ser feito por meio da avaliação das lesões, microscopia direta de pelos e crostas, biopsia, cultivo em placas com meios específicos, além da lâmpada de Wood; porém mesmo com essa variedade de métodos disponíveis, a identificação das espécies envolvidas ainda representa uma grande dificuldade na rotina laboratorial da clínica veterinária (Cavalcanti et al., 2002). Várias técnicas moleculares têm sido aplicadas para a identificação laboratorial de espécies de dermatófitos, sendo consideradas mais estáveis, rápidas e precisas do que aquelas que se baseiam nas características fenotípicas (Gutzmer et al., 2004, Shehata et al., 2008). Dentre elas está a PCR (Shehata et al., 2008).

Objetivou-se neste estudo comparar a técnica da PCR-RFLP com a cultura como métodos de identificação de dermatófitos que acometem cães e gatos.

\section{Material e Métodos}

As amostras foram coletadas no Hospital Veterinário da Universidade Federal Rural de Pernambuco e enviadas para o Laboratório de Doenças Infecciosas dos Animais Domésticos do Departamento de Medicina Veterinária, onde foram processadas. $\mathrm{O}$ material analisado consistiu de amostras de pelos e/ou crostas, obtidas pelo método de avulsão e/ou raspado cutâneo das 
bordas das lesões com lâmina de bisturi estéril, conforme descrito por Cruz (2010).

Foram analisadas 150 amostras clínicas de animais com dermatopatias. $\mathrm{O}$ exame direto foi realizado utilizando-se o clarificante hidróxido de potássio (30\%), em escamas de pele e pelos para identificação de estruturas de parasitismo como hifas e artroconídios de acordo com Muller and Kirk, 1996. As amostras de pelos e/ou crostas foram cultivadas em ágar dextrose Sabouraud adicionado de extrato de levedura, cloranfenicol e ciclo-heximida. As placas foram incubadas aerobicamente em temperatura ambiente (25$27^{\circ} \mathrm{C}$ ) e examinadas diariamente por até cinco semanas de acordo com $\underline{\text { Cruz (2010) }}$.

O DNA das amostras clínicas e do micélio aéreo das colônias foi extraído utilizando o kit de extração DNeasy Blood \& Tissue (QIAGEN ${ }^{\circledR}$, Hilden - Germany), e o protocolo de extração de DNA de tecidos em geral, que pertence ao kit. Ao final os tubos identificados foram armazenados no freezer.

As reações de amplificação do DNA foram realizadas para um volume final de $25 \mu \mathrm{L}$, contendo: $5 \mu \mathrm{L}$ de DNA genômico; $1 \mu \mathrm{L}$ de cada primer a $10 \mu \mathrm{M}$ (ITS-1 e ITS-4); 5,5 $\mu \mathrm{L}$ de Água Mili-Q ultrapura e 12,5 $\mu \mathrm{L}$ de Top Taq ${ }^{\mathrm{TM}}$ Master Mix (QIAGEN ${ }^{\circledR}$, Hilden - Germany), de acordo com instruções do fabricante. Foi utilizado como controle negativo água ultra pura e como controles positivos, DNA extraído de colônias de $M$. canis (URM 6273), M. gypseum (URM 6921) e $T$. mentagrophytes (URM 6211), provenientes da Coleção de Culturas - Micoteca URM Departamento de Micologia, Centro de Ciências Biológicas da Universidade Federal de Pernambuco (CCB/UFPE). Os primers utilizados foram: ITS1 (5' TCCGTAGGTGAACCTGCGG 3'); e ITS4 (5' TCCTCCGCTTATTGATATGC 3') (White et al., 1990) (Eurofins MWG Operon), que amplificam as regiões ITS I, 5,8S e ITS II do DNA ribossomal (rDNA). O protocolo térmico para a amplificação foi o recomendado por Mirzahoseini et al. (2009) que consistiu de 35 ciclos de $93^{\circ} \mathrm{C}$ por $1 \mathrm{~min}, 58^{\circ} \mathrm{C}$ por $1 \mathrm{~min}$ e $72^{\circ} \mathrm{C}$ por $1 \mathrm{~min}$, seguidos de uma etapa de extensão final de $72^{\circ} \mathrm{C}$ por $7 \mathrm{~min}$. Após a amplificação, o produto de PCR foi colocado em gel de agarose $2 \%$, corado com Blue Green Loading Dye I (LGC Biotecnologia) e posto em cuba de eletroforese com tampão Tris-acetato-EDTA (1X) (Amresco $\left.{ }^{\circledR}\right)$ para posterior visualização sob a luz ultravioleta $\mathrm{e}$ fotodocumentação.
Os amplicons foram digeridos pela enzima de restrição BseBI (Jena Bioscience, Jena-Germany), que reconhece a sequência 5' $\mathrm{CC} / \mathrm{WGG} 3$ ', seguindo o protocolo térmico recomendado pelo fabricante. As reações foram calculadas para um volume final de $12,5 \mu \mathrm{L}$, contendo: $2,5 \mu \mathrm{L}$ tampão da enzima (10x buffer B2), $6 \mu \mathrm{L}$ do produto da PCR (amplicons), 0,2 $\mu \mathrm{L}$ da enzima BseBI e 3,8 $\mu \mathrm{L}$ de $\mathrm{H}_{2} \mathrm{O}$. Após o período de corte enzimático as amostras foram colocadas no freezer para inativação da enzima e posterior avaliação por eletroforese em gel de agarose $2 \%$.

Para o estudo de concordância entre os métodos de diagnóstico utilizou-se o coeficiente de Kappa $(K)$ e a interpretação dos valores $K$ adotadas foram: $0,00-0,20=$ concordância fraca; $0,21-0,40=$ regular; $0,41-0,60=$ moderada; 0,61 - $0,80=$ boa; $0,81-1,00=$ muito boa, valores negativos são interpretados como equivalentes a 0,00 (Landis and Koch, 1977). Para o cálculo de concordância utilizou-se o programa computacional Bioestat versão 5.0.

Projeto aprovado pela Comissão de Ética no Uso de Animais da Universidade Federal Rural de Pernambuco (CEUA-UFRPE), sob a Licença $n^{\circ}$ 017/2013.

\section{Resultados}

Analisando-se os resultados das amostras clínicas, observou-se que 5,3\% (8/150) foram positivos na cultura e $6 \%(9 / 150)$ apresentaram um padrão de bandas semelhante ao observado nas amostras controle, na PCR-RFLP (Tabela 1).

As análises de concordância entre os resultados observados na cultura e na PCR-RFLP estão apresentadas na Tabela 1 . Na figura 1 estão os padrões de bandas diferenciados para cada espécie estudada, observados após PCR-RFLP.

Quando comparados os resultados obtidos na PCR-RFLP com os da cultura (Tab. 1), observouse uma sensibilidade de $87,5 \%$. Observou-se também uma concordância muito boa entre os resultados, quando se comparou os valores de Kappa. Das nove amostras que apresentaram um padrão de bandas semelhante ao padrão verificado nos controles positivos, 66,7\% (6/9) foram identificadas como $M$. canis e 33,3\% (3/9) como T. mentagrophytes.

As amostras 03, 05, 07, 09, 10 e 11 apresentaram padrões de bandas semelhantes aos observados nas amostras de controles positivos, porém com menor intensidade. 
Estas mesmas amostras foram cultivadas em placas contendo ágar Sabouraud suplementado com cloranfenicol e ciclo-heximida, e após período de incubação foram observadas colônias de fungos dermatófitos, que depois de observadas as características macro e microscópicas, identificaram-se M. canis (amostras 03, 05, 07, 10 e 11) e T. mentagrophytes (amostra 09), o que demonstra a potencialidade da técnica para identificação das espécies diretamente de amostras clínicas, sem a necessidade de aguardar o período entre o cultivo e a identificação para se iniciar o tratamento.

Tabela 1. Análise de concordância entre resultados da cultura e da PCR-RFLP para fungos dermatófitos isolados de amostras clínicas de cães e gatos atendidos no Hospital Veterinário da UFRPE em 2011 e 2012

\begin{tabular}{|c|c|c|c|c|c|c|c|c|}
\hline \multirow{3}{*}{ PCR-RFLP } & \multicolumn{4}{|c|}{ Microbiológico } & \multirow{3}{*}{ Valor de P } & \multirow{3}{*}{ Kappa } & \multirow{3}{*}{ Sens. $(\%)$} & \multirow{3}{*}{ Espec. $(\%)$} \\
\hline & \multicolumn{2}{|c|}{ Positivo } & \multicolumn{2}{|c|}{ Negativo } & & & & \\
\hline & F.A. & F.R. $(\%)$ & F.A. & F.R. $(\%)$ & & & & \\
\hline Positivo & 7 & 77,8 & 2 & 22,2 & \multirow{2}{*}{$<0,0001$} & \multirow{2}{*}{0,813} & \multirow{2}{*}{87,5} & \multirow{2}{*}{98,6} \\
\hline Negativo & 1 & 0,7 & 140 & 99,3 & & & & \\
\hline
\end{tabular}

F.A: Frequência absoluta; F.R.: Frequência relativa; Sens.: Sensibilidade; Espec.: Especificidade.

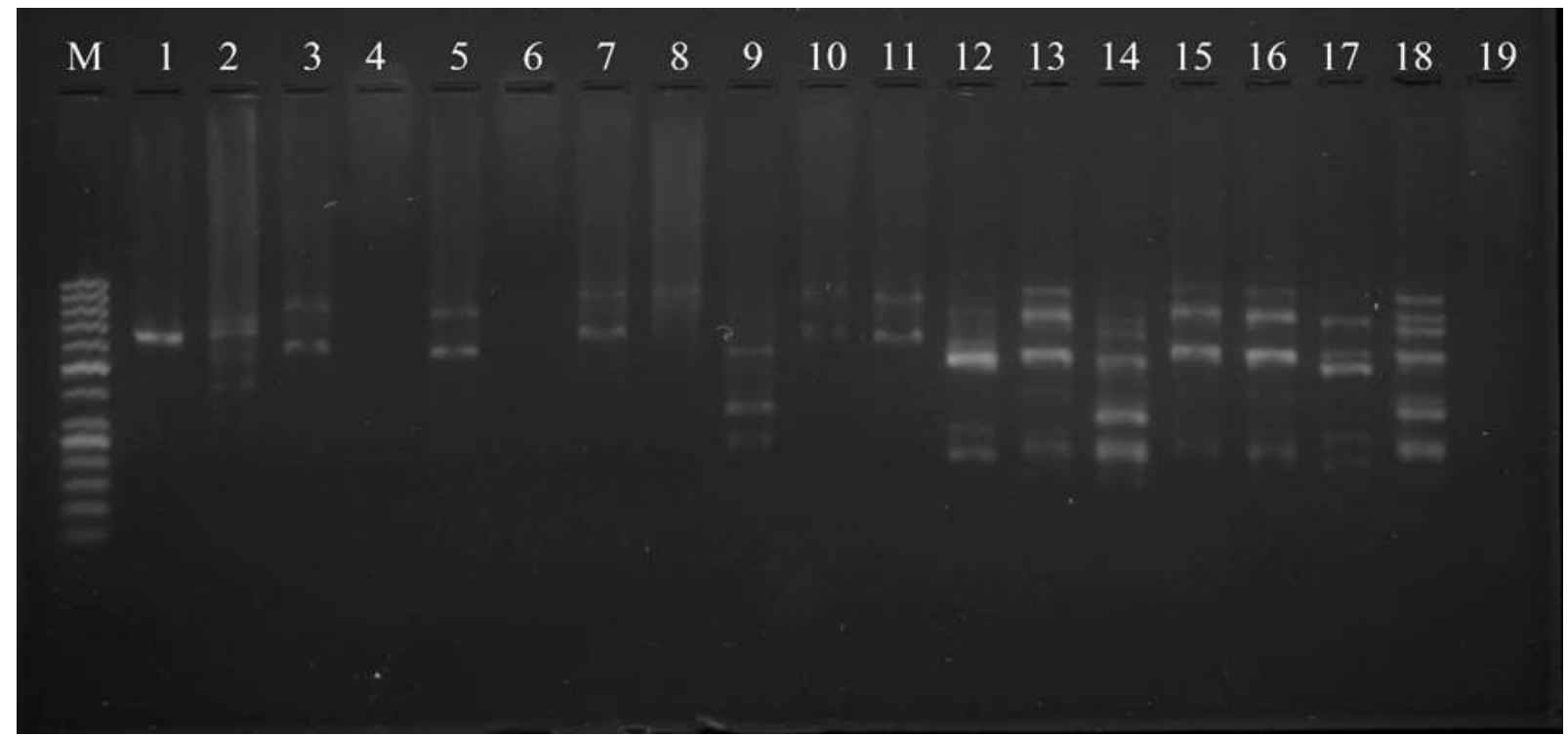

Figura1. Gel de agarose $2 \%$ com os resultados obtidos na PCR-RFLP. M: marcador molecular 50 pb (Fermentas $\left.{ }^{\circledR}\right) ; 01-11$ : Amostras clínicas; 12 e 17: M. gypseum (URM 6921); 13, 15 e 16: M. canis (URM 6273); 14 e 18: T. mentagrophytes (URM 6211); 19: controle negativo.

Como pode ser observado na figura 1 , por meio da intensidade do brilho das bandas, a quantidade de DNA presente nas amostras extraídas de pelos é bem menor do que nas de micélio aéreo, o que pode justificar a diferença nos padrões apresentados pelas amostras clínicas.

\section{Discussão}

A PCR-RFLP, uma variação da PCR, permite a obtenção de uma série de fragmentos de DNA de tamanhos diferentes que dão origem a um padrão de bandas, e baseia-se na presença de sítios de restrição na região amplificada do DNA-alvo que pode ser determinada por intermédio do processamento do produto da PCR, com uma ou mais endonucleases de restrição (Vergara et al., $\underline{2006}$ ).
Jackson et al. (1999) realizaram a amplificação da região ITS de fungos dermatófitos utilizando primers universais, seguida da digestão enzimática dos produtos amplificados com a endonuclease de restrição $M v a I$ e observaram padrões diferenciados para maioria das espécies analisadas.

Neste estudo observou-se concordância entre os resultados da cultura e da PCR-RFLP em 98\% (147/150) das amostras analisadas. MachouartDubach et al. (2001) observaram que 74 das 75 amostras analisadas, em seu trabalho, foram concordantes nos resultados em ambas as técnicas, considerando a técnica molecular adequada para o diagnóstico rápido de dermatofitose em amostras clínicas humanas. Wisselink et al. (2011) utilizaram a PCR em tempo real para identificação 
de dermatófitos em pacientes humanos, comparando-a com a cultura e observaram $97,41 \%$ de concordância entre os resultados em nível de gênero.

Vergara et al. (2006) padronizaram uma técnica de PCR para o diagnóstico de dermatófitos e observaram uma concordância de 93,3\% entre os resultados obtidos na PCR e os obtidos com os métodos tradicionais de diagnóstico, quando analisaram 30 cepas pertencentes a esse grupo de fungos, no entanto, quando analisaram 30 amostras clínicas positivas e negativas de pacientes humanos com infecção ativa, observaram $100 \%$ de concordância entre os resultados obtidos, o que sugeriu que a PCR é uma técnica que oferece grandes vantagens na identificação dos fungos dermatófitos.

Gutzmer et al. (2004) desenvolveram um método de PCR para rápida detecção e diferenciação de fungos em amostras dermatológicas, utilizando sete pares de primers localizados no DNA ribossômico (rDNA) e na região ITS e obtiveram informações mais conclusivas a respeito do diagnóstico, em $23,7 \%$ (9/38) dos casos, pela PCR quando comparado aos resultados obtidos nos métodos convencionais.

Outras variações da PCR vêm sendo utilizadas no diagnóstico da dermatofitose em humanos e animais com resultados significativos quanto à identificação de gêneros e espécies a partir de amostras cultivadas, o que indica a possibilidade da identificação desses agentes diretamente da amostra colhida do paciente sem a necessidade da realização de uma cultura, reduzindo em muito o tempo de espera pelo resultado e a perda do cultivo por contaminantes (Gräser et al., 1998, Liu et al., 2000, Faggi et al., 2001, Shehata et al., 2008).

A partir da comparação entre os métodos tradicionais de identificação dos dermatófitos e técnicas moleculares, observa-se o quanto estas últimas podem contribuir, não só na questão tempo, como também uma identificação mais rápida e eficaz das dermatofitoses permite o seu controle, e o estudo da epidemiologia desta doença pelo conhecimento de espécies endêmicas geograficamente, além de contribuir para redução de casos de resistência a antifúngicos, colabora para o desenvolvimento de novas drogas com concentrações inibitórias espécie-específica (Lemsaddek, 2008).

\section{Conclusão}

A partir da análise de concordância entre os resultados obtidos pelo método padrão e a técnica molecular, conclui-se que a PCR-RFLP apresentou grande potencial de identificação de dermatófitos em amostras clínicas de cães e gatos, no entanto, ressalta-se a necessidade de se ampliar esses estudos, para futura indicação da PCR-RFLP na rotina laboratorial.

\section{Referências bibliográficas}

Cavalcanti, J. N., Guerra, J. L., Gambale, W., Corrêa, B. \& Paula, C. R. 2002. Histopathologic and mycologic aspects of experimental infection of guinea pigs with Microsporum canis. Brazilian Journal of Veterinary Research and Animal Science, 39, 238-243.

Coelho, A. C., Alegria, N. \& Rodrigues, J. 2008. Isolamento de dermatófitos em animais domésticos em Vila Real, Portugal. Arquivo Brasileiro de Medicina Veterinária e Zootecnia, 60, 1017-1020.

Costa, F. V. A. 2010. Determinação da variabilidade genotípica entre isolados de Microsporum canis. Faculdade de Veterinária. Universidade Federal do Rio Grande do Sul, Porto Alegre.

Cruz, L. C. H. 2010. Micologia veterinária. Revinter, Rio de Janeiro.

Faggi, E., Pini, G., Campisi, E., Bertellini, C., Difonzo, E. \& Mancianti, F. 2001. Application of PCR to distinguish common species of dermatophytes. Journal of Clinical Microbiology, 39, 3382-3385.

Gräser, Y., El Fari, M., Presber, W., Sterry, W. \& Tietz, H. J. 1998. Identification of common dermatophytes (Trichophyton, Microsporum, Epidermophyton) using polymerase chain reactions. British Journal of Dermatology, 138, 576-582.

Gutzmer, R., Mommert, S., Küttler, U., Werfel, T. \& Kapp, A. 2004. Rapid identification and differentiation of fungal DNA in dermatological specimens by LightCycler PCR. Journal of Medical Microbiology, 53, 1207-1214.

Jackson, C. J., Barton, R. C. \& Evans, E. G. V. 1999. Species identification and strain differentiation of dermatophyte fungi by analysis of ribosomal-DNA intergenic spacer 
regions. Journal of Clinical Microbiology, 37, 931-936.

Landis, J. R. \& Koch, G. G. 1977. The measurement of observer agreement for categorical data. Biometrics, 33, 159-174.

Lemsaddek, A. 2008. Estudo de dermatófitos por métodos moleculares: identificação, resistência a antifúngicos e virulência. Faculdade de Ciências. Universidade de Lisboa, Lisboa.

Liu, D., Coloe, S., Baird, R. \& Pedersen, J. 2000. Application of PCR to the identification of dermatophyte fungi. Journal of Medical Microbiology, 49, 493-497.

Liu, D., Pearce, L., Lilley, G., Coloe, S., Baird, R. \& Pedersen, J. 2002. PCR identification of dermatophyte fungi Trichophyton rubrum, $T$. soudanense and T. gourvilii. Journal of Medical Microbiology, 51, 117-122.

Machouart-Dubach, M., Lacroix, C., de Chauvin, M. F., Le Gall, I., Giudicelli, C., Lorenzo, F. \& Derouin, F. 2001. Rapid discrimination among dermatophytes, Scytalidium spp., and other fungi with a PCR-restriction fragment length polymorphism ribotyping method. Journal of Clinical Microbiology, 39, 685-690.

Muller, G. H. \& Kirk, R. W. 1996. Dermatologia de pequenos animais. 5. ed. Rio de Janeiro: Interlivros, 1130p.

Mirzahoseini, H., Omidinia, E., ShamsGhahfarokhi, M., Sadeghi, G. \& RazzaghiAbyaneh, M. 2009. Application of PCR-RFLP to rapid identification of the main pathogenic dermatophytes from clinical specimens. Iranian Journal of Public Health, 38, 18-24.
Quinn, P. J., Markey, B. K., Carter, M. E., Donnelly, W. J. \& Leonard, F. C. 2005. Microbiologia veterinária e doenças infecciosas. Artmed, Porto Alegre.

Shehata, A. S., Mukherjee, P. K., Aboulatta, H. N., El Akhras, A. I., Abbadi, S. H. \& Ghannoum, M. A. 2008. Single-step PCR using (GACA) 4 primer: utility for rapid identification of dermatophyte species and strains. Journal of Clinical Microbiology, 46, 2641-2645.

Vergara, C. C., Parcha, C., Pineda, J. \& Reyes Arenas, E. 2006. Estandarización de una técnica de amplificación genómica (PCR) para el diagnóstico de Dermatofitos. Ciencia \& Trabajo, 8, 167-171.

White, T. J., Bruns, T., Lee, S. J. W. T. \& Taylor, J. W. 1990. Amplification and direct sequencing of fungal ribosomal RNA genes for phylogenetics. PCR protocols: a guide to methods and applications, 18, 315-322.

Wisselink, G. J., Van Zanten, E. \& Kooistra-Smid, A. M. D. 2011. Trapped in keratin; a comparison of dermatophyte detection in nail, skin and hair samples directly from clinical samples using culture and real-time PCR. Journal of Microbiological Methods, 85, 6266.

\section{Article History:}

Received 16 November 2016

Accepted 17 January 2017

Available on line 2 February 2017

License information: This is an open-access article distributed under the terms of the Creative Commons Attribution License 4.0, which permits unrestricted use, distribution, and reproduction in any medium, provided the original work is properly cited 